\title{
O PROBLEMA DA METAFÍSICA EM HEIDEGGER NO PERÍODO DE GESTAÇÃO DE SER E TEMPO
}

Mafalda Blanc

(Universidade de Lisboa)

\section{A aporética da Metafísica: a ausência de uma compreensão unitária do ser}

Heidegger acedeu à filosofia, ainda jovem estudante liceal, pela leitura da dissertação de F. Brentano "Da Significação múltipla do Ente em Aristóteles", de 1862. A questão que o interpelou e lançou na aventura do pensar foi, em suas palavras, a seguinte: "se o ente se diz numa significação múltipla, qual é então a significação directriz e fundamental? Que significa ser?" $O$ que aqui se interroga não concerne directamente $o$ conteúdo temático da Metafísica - não se pergunta pelo ente, não se busca uma definição da sua essência ou uma causa explicativa para a sua existência -,antes diz respeito ao horizonte de compreensão em que se funda toda a interpretação do ente, toda a possível concepção do ser. Motivada por uma exigência crítica de clarificação radical e validação como que transcendental, bem ao gosto de seu tempo, a problemática de Heidegger, sem nunca ceder ao agnosticismo metafísico, move-se assim, desde o início, no âmbito de uma procura de fundamentação, visando mais uma Metafísica da Metafísica do que uma nova interpretação da realidade.

Uma familiaridade crescente com o pensamento helénico, em particular Aristóteles, fê-lo compreender que os Gregos entendiam o ser como

\footnotetext{
${ }^{1}$ Heidegger, Zur Sache des Denkens (1962-1973):Mein Weg in die Phänomenologie, Gesamtausgabe (que passaremos a abreviar pela sigla G.A.), t. 14, Frankfurt a. Main: Vittorio Klostermann, 2007, p. 93:"Wenn das Seiende in mannigfacher Bedeutung gesagt wird, welches ist dann die leitende Grundbedeutung? Was heisst Sein?"
}

Philosophica, 43, Lisboa, 2014, pp. 99-114. 
a "presença" (Anwesenheit) do presente, ou seja, a actualidade do que, tendo-se efectivado, aí está completo, na perfeição acabada da sua essência. Tal é, com efeito, a tese fundamental dos primeiros livros da Metafisica, quando, da quádrupla significação do ente - o ente enquanto substância ou acidente, o ente segundo as categorias, segundo o acto e a potência e o ente enquanto verdadeiro ou falso -, o Estagirita acaba por eleger a acepção categorial e, nela, a essência, primeira das categorias, enquanto significação reitora, a que as demais se reportam. ${ }^{2} \mathrm{O}$ ser ele próprio (kat'autó), que, num primeiro momento, foi caracterizado como" substrato material" (upokeimenon), acaba por ser reconduzido à forma, direccionando-se assim a ontologia para a constituição de uma "ousiologia" ou doutrina da essência. ${ }^{3}$ Com efeito, os seres sensíveis, compostos de matéria e de forma, apesar de estarem separados no interior de si mesmos entre aquilo que eles são na sua essência e aquilo que a cada momento dela vão consignando - e isso porque estão projectados no movimento -, nem por isso deixam de tender e convergir, ao menos assimptoticamente, para a sua forma, graças à dialéctica do acto e da potência e à prevalência do primeiro sobre a segunda. ${ }^{4}$ De modo que a pergunta socrática pelo "que é", apesar de não esgotar toda a riqueza de determinação do indivíduo - devendo ao género acrescentar-se qualidades e atributos acidentais por si - acaba por consignar o fundamental do que a coisa é na sua suficiência essencial, sem a adjunção de mais predicados. Apesar de relevar a importância fundamental do movimento e do tempo, a ele associado, na realização da substância, Aristóteles acaba por anuir ao essencialismo platónico, confirmando a hegemonia da presença sem a referir explicita e tematicamente ao tempo. A sua compreensão do tempo, centrada no "agora", não lho permitia, condicionada que estava pela sua interpretação do ser como presença. ${ }^{5} \mathrm{O}$ fundador da Metafísica legaria assim à posteridade uma impensada sobredeterminação do ser pelo tempo, que a filosofia ulterior, antes de Heidegger, não se lembraria de questionar.

Tudo isto nos permite esclarecer agora o que atrás afirmávamos, a saber, que a problemática de Heidegger, embora mantenha uma relação

${ }^{2}$ Aristóteles, Metafísica, 1. IV, 2, 1003b, 5-20; 1. V, 7, 8;1. VII, 1.

${ }^{3}$ Ibid., 1. VII, 3 e segs.

${ }^{4}$ Conf. Aristóteles, Metafísica, 1. VIII, 8, onde se refere a tripla anterioridade do acto sobre a potência, segundo a noção, segundo a geração e o tempo e do ponto de vista ontológico. A este propósito, veja-se ainda os cursos de 1930/31 Vom Wesen der Menschlichen Freiheit. Einleitung in die Philosophie, G.A., t. 31, §§ 8-10, pp. 55-112 e o curso, de 1931, Aristoteles, Metaphysik VIII, 1-3. Vom Wesen und Wirklichkeit der Kraft, G.A., t. 33.

${ }^{5}$ Veja-se Aristóteles, Física, 1. IV, caps. 11 e 12. 
verdadeiramente originária com a tradição metafísica, não se inscreve na continuidade desta, não perpetua o seu modo ôntico de questionar, antes inquire sobre a essência da Metafísica, sobre o que funda em geral as suas respostas à questão do ente e preside ao desvelamento do ser como presença. Até porque a rainha das ciências, talvez porque enferme desde a sua fundação de uma falta de clareza essencial acerca do solo em que assenta a sua interpretação do ser, transporta consigo, além do mais, uma aporética própria concernente à articulação interna da diversidade de acepções do ser, que se impõe elucidar antes de qualquer intento construtivo. Ela concerne quatro grandes grupos de problemas, que se polarizaram em teses fundamentais acerca do ser. São elas: a tese medieval, de origem aristotélica, da distinção entre a essência e a existência como constituintes ontológicos do ente; a tese moderna da distinção entre a natureza e o espírito como domínios ou modificações principais do ser; a tese kantiana acerca do ser, não como predicado real, mas como posição absoluta, a qual já anuncia uma certa compreensão da diferença ontológica; e, por último, a tese lógica acerca do carácter veritativo do ser, que estatui que todo o ente, qualquer que seja o seu modo de ser, se deixa abordar pela cópula do juízo. ${ }^{6}$

Para Heidegger, se a clarificação desta problemática é condição da sistemática do ser, ou seja, da coerência interna do edifício da Metafísica, ela não é possível, contudo, sem a prévia explicitação do sentido do ser. O tempo, como adiantámos atrás, afigurar-se-á ao nosso filósofo um princípio plausível de solucionamento, suficientemente flexível e articulado para justificar a diferenciação e a unidade interna do ser. Faltava-lhe, no entanto, o instrumento adequado para levar a cabo a investigação da relação entre o ser e o tempo, e isso foi o que lhe proporcionou o seu contacto com Husserl e a aprendizagem, por ele, do exercício da fenomenologia como método explicitativo dos actos da consciência nas suas dimensões noético-noemáticas. Com efeito, não se debruçava ela, com o seu conceito de intencionalidade, sobre a significação ideal que a consciência empresta à experiência, já desde o nível da percepção, e que não releva nem do sensível nem do psíquico?

A sexta "Investigação Lógica", em particular, na distinção que estabelece entre intuição sensível e categorial, foi para Heidegger determinante no que concerne a elucidação do sentido da essência. ${ }^{7}$ Com efeito, ao afirmar que o universal categorial não é nem um momento dos objectos externos, nem um elemento das vivências psíquicas do sujeito cogni-

\footnotetext{
${ }^{6}$ Heidegger faz a discussão das quatro teses sobre o ser no curso de Marburgo de 1927 Die Grundprobleme der Phänomenologie, G.A., t. 24.

${ }^{7}$ Veja-se o texto já citado Mein Weg in die Phänomenologie, G.A., t. 14, pp. 98.
} 
tivo, mas uma estrutura constituída pelos actos relacionantes da função judicativa, que pode ser intuitivamente confirmada a partir da matéria dos respectivos actos fundantes, Husserl, aos olhos de Heidegger, aproximava-se providencialmente do trabalho de investigação categorial iniciado por Platão e Aristóteles, provando, contra todo o agnosticismo kantiano, que as formas categoriais constituem dados trans-subjectivos, que enformam os fenómenos na sua individualidade ôntica concreta e podem ser conceptualizados, no "como" do seu mostrar-se. ${ }^{8}$

Porém, uma divergência de fundo quer quanto ao entendimento da filosofia quer quanto à sua finalidade - para não falar de uma diversa formação, científica num caso, metafísica e teológica no outro - impedia de princípio um verdadeiro entendimento entre os dois filósofos. Husserl exigia da filosofia o rigor de uma ciência e a incumbência de uma fundação epistemológica das ciências; já o seu discípulo entendia-a a partir da e como Metafísica, perguntando pela sua possibilidade e viabilização como saber. Era, pois, natural que essa divergência se manifestasse na interpretação da Fenomenologia, do seu sentido e alcance, em particular no que diz respeito às noções de intencionalidade e de fenómeno. Quanto àquela, Heidegger entende-a não do ponto de vista idealista da consciência cognitiva, mas daquele outro, realista, da "intentio" escolástica, em que o movimento de abertura do pensar ao ser, longe de constituir uma iniciativa do sujeito, procede já do próprio ser que o funda e precede; e uma vez que o ser não é imanente ao pensar, mas o inverso, torna-se possível interpretar a essência da fenomenalidade vendo nela o teor significativo e substantivo do próprio ser no seu aparecer. Quanto ao fenómeno, ele não se reduz a essa presença objectiva e sem resto que Husserl entronizava como um modelo de evidência num aparecer plenamente ajustado à expectativa da consciência; sempre excedido por uma zona de sombra e inaparência que reenvia, para lá de si mesma, para uma fonte escondida que a trabalha e para uma última doação, ele obriga a consciência a ir mais além do horizonte da actualidade, a transpor-se no possível de molde a aí projectar o quadro mais adequado à recepção do que vem à presença.

${ }^{8}$ Ibid., pp. 98-99 e Husserl, Logische Untersuchungen, VI, § 41, 4. ${ }^{a}$ ed., Halle: M. Niemeyer, 1928, p. 663, onde afirma:"Und wo sich die neue Intention durch unterliegende Anschauung adäquat erfüllt, erweist sie ihre objective Möglichkeit bzw. Die Möglichkeit oder Realität des Allgemeinen." [E onde a nova intenção se preenche adequadamente por meio da intuição subjacente, prova-se a sua possibilidade objectiva. A possibilidade ou realidade do geral.] 


\section{A recepção da Escolástica no confronto com o Neokantismo e a Fenomenologia}

Se, desde jovem, Heidegger está convencido que em filosofia só se avança pelo aprofundamento de um círculo limitado de questões que, no caso da Metafísica, convergem para a questão do sentido do ser, já no que concerne ao tempo - chave do seu solucionamento - o reconhecimento do seu papel lapidar foi o fruto de um lento trabalho de amadurecimento, a que não foi estranha a experiência da sua participação na primeira grande Guerra mundial. ${ }^{9}$ A isso nos referiremos mais adiante. Antes, porém, convém adiantar algo acerca da formação filosófica do nosso autor, ou seja, acerca da Neo-escolástica e do Neokantismo, que dominavam o meio académico da época, e a partir dos quais ocorreu a sua recepção de Aristóteles e da Fenomenologia. A primeira, na sua versão católica, foi a sua porta de entrada em Metafísica, tendo-lhe incutido, com a ideia da transcendentalidade do ser, o realismo e a tensão onto-teológica; o segundo, que pululava nos meios académicos da época, foi-lhe transmitido pelo seu mestre Rickert na versão da filosofia dos valores e, embora não correspondesse ao conjunto das preocupações do jovem filósofo, deu-lhe uma consciência crítica do problema da possibilidade da Metafísica e da sua dependência da questão da objectividade do conhecimento. ${ }^{10}$

Na sua tese de Habilitação sobre "A Doutrina das Categorias e da Significação em Duns Escoto", de 1915, o filósofo afirma que o problema das categorias está dependente da clarificação do conceito de ser - essa proto-categoria, a que os Medievais, em particular Escoto, deram uma extensão universal. ${ }^{11}$ Com efeito, como transcendental o ser inclui não apenas a esfera do ser real - a natureza, como pensava Rickert com a lógica do seu tempo, mas ainda a esfera ideal das entidades lógicas e dos valores, que não são "coisas irreais", mas modos de ser. Assumindo a transcendentalidade do ser, Heidegger quer fundá-lo enquanto verum,

\footnotetext{
${ }^{9}$ Conf. Heidegger, Frühe Schriften (1912-1916): Die Kategorien-und Bedeutungslehre des Duns Scotus, G.A., t. 1, p. 197.

${ }^{10}$ Rickert foi o orientador da Dissertação de Doutoramento de Heidegger Die Lehre vom Urteil im Psychologismus, de 1913,onde, na linha de seu mestre, defende, contra o psicologismo, a autonomia da esfera da lógica face à vivência psíquica, temporal e mutável, considerando, por isso, a essa luz a significação do juízo independente do tempo e do espaço. Veja-se, a este propósito, G.A.,T.1, pp. 265 e segs.

${ }^{11}$ Veja-se Frühe Schriften:Die Kategorien- und Bedeutungslehre des Duns Scotus, G.A.,t. 1, 1. ${ }^{\text {a }}$., cap. 1 , p. 214 e segs.
} 
partindo de uma análise transcendental que tenha em conta o princípio moderno da imanência e o papel do sujeito na sua função constitutiva do objecto, exigências estas que o realismo escolástico ignorava. ${ }^{12}$

Sob a influência de E. Lask, o filósofo situa a verdade ao nível ante-predicativo, interpretando-a como apreensão do ente (a matéria, o dado real e transcendente enquanto, em plena autonomia, determina com a sua manifestação imediata o pensar do sujeito) à luz do ser, compreendido como a forma das formas. Porém, não interpreta o sujeito cognitivo de forma lógica e atemporal, mas como condicionado, na interpretação que faz do sentido da experiência, pelo contexto cultural e histórico em que se insere. ${ }^{13} \mathrm{~A}$ seu ver, longe de produzir um sentido absoluto, normativo, capaz de julgar as diversas "mundividências" históricas, o pensar só acede a uma verdade relativa, parcial, dispersa por uma pluralidade de interpretações e expressões. É que, como Hegel mostrou, a verdade, o sentido, mesmo se sempre referidos ao absoluto, só se manifestam historicamente.

Heidegger não tem, no entanto, a mínima intenção de ceder ao relativismo. Defende, com efeito, quer a validade absoluta do conhecimento verdadeiro, quer a finitude histórica do espírito que o constitui, numa tentativa de difícil conciliação entre o tempo e a eternidade, o relativo e o absoluto, a história e a filosofia, o contingente e o necessário. Considera para tal insuficiente a abordagem epistemológica da consciência e faz apelo à fenomenologia, à sua descrição concreta da vida da subjectividade na pluralidade das suas dimensões. Com efeito, só uma análise das essências e estruturas intencionais dos actos, em que elas se dão à consciência, pode avaliar se e como é que o espírito humano, embora individual e histórico, é capaz de captar o sentido válido e absoluto das coisas; decidir, portanto, da imanência ou transcendência do ser afirmado no juízo verdadeiro e, por conseguinte, da possibilidade da Metafísica. Psicologia, lógica, ontologia não se excluem nessa análise ontológica do espírito enquanto capaz, na concretude histórica do seu existir, de uma compreensão do ser. É que o sujeito noético não esgota o significado metafisicamente mais importante do espírito, que reside na sua orientação teleológica para uma norma absoluta e transcendente, de consistência entitativa. ${ }^{14} \mathrm{E}$ uma vez que o sujeito absoluto do idealismo fica excluído

${ }^{12}$ Sobre o verum como transcendental e a realidade lógica, veja-se Op. Supra-citada, cap. 2, p. 265 e segs.

${ }^{13}$ Conf. Ibid., conclusão, p.399 em diante, onde faz a análise do sujeito histórico e apela ao confronto com Hegel.

${ }^{14}$ Ibidem, pp. 405-406:"Man vermag die Logik und ihre Probleme überhaupt nicht im wahre Lichte zu sehen, wenn nicht der Zusammenhang, aus dem heraus sie gedeutet werden, ein translogischer wird. Die Philosophie kann ihre eigentliche 
pela experiência incontornável da finitude, só resta interpretar tal abertura transcendental à luz de uma Metafísica teológica, fazendo apelo ao Deus real e transcendente da Onto-teologia medieval.

$\mathrm{Na}$ linha da reforma do pensamento católico encetada por Maréchal e Blondel através do diálogo com o pensamento moderno e o kantismo, Heidegger procurou, por conseguinte, na sua tese de Habilitação à docência encontrar uma base sólida e consistente para a Metafísica, que respondesse às exigências do criticismo sem cair no imanentismo e no agnosticismo. Reivindicando um realismo crítico, coloca-se à partida no terreno ontológico, recusando a autonomia da consciência; admite, porém, o ponto de partida kantiano do objecto fenomenal e o método transcendental de análise. Não deixa, contudo, de introduzir no espírito um dinamismo intelectual ignorado pela "Crítica", entendendo a ordem da acção e da finalidade como o mais firme ponto de apoio da afirmação absoluta do ser e a condição última de possibilidade do conhecimento dos objectos, ao mesmo tempo que tem Deus como o termo último da ascensão do espírito na escala dos valores e a garantia do conhecimento humano.

Contestando a tese positivista da lógica contemporânea, que restringe o ser à realidade empírica, Heidegger confere-lhe a amplitude e dignidade de um transcendental e, fazendo uma leitura ontológica da "Lógica transcendental", interpreta as categorias, não como meras funções lógicas do entendimento, mas como estruturas entitativas que o pensar descobre no material da experiência. Assim, todas as regiões ônticas, mesmo as da verdade e dos valores - escalonadas hierarquicamente da natureza a Deus, segundo um princípio de ordenação analógica - devem ser tomadas como modos do ser acessíveis ao conhecimento. Mas o próprio ser, proto-categoria unificadora do sistema das categorias e condição última do conhecimento objectivo, não deve ser considerado independentemente do sujeito que o pensa, apresentando-se à consciência sob o modo peculiar da objectividade dos objectos, das formas categoriais constituídas pelo pensar, as quais não existem mas valem.

Optik, die Metaphysik, auf die Dauer nicht entbehren. Für die Wahrheitstheorie bedeutet das die Aufgabe einer letzten metaphysisch-teleologischen Deutung des Bewusstseins." (sublinhado no texto) [Não se pode ver a lógica e os seus problemas numa luz verdadeira, se a conexão a partir da qual elas são interpretadas não assume uma natureza translógica. Com o tempo, a filosofia não pode dispensar o que constitui a sua óptica própria, a Metafísica. Isso significa que se impõe, para uma teoria da verdade, a tarefa de levar a cabo uma última interpretação teleológica e metafísica da consciência.] 


\section{A ruptura existencial e o projecto de refundação da Metafísica}

Terminado o período de formação da sua problemática pessoal no confronto com o contexto filosófico do seu tempo, Heidegger vai consagrar-se à tarefa, que se tinha proposto na conclusão da sua tese, de renovação da Metafísica à luz de um diálogo com o pensamento moderno numa perspectiva que concilie realismo e idealismo, a anterioridade do ser sobre o pensar e as prestações subjectivas do "eu penso", as quais emprestam sentido à realidade. Mas cedo se apercebe das dificuldades de articular as verdades absolutas e atemporais da lógica com a temporalidade e historicidade da existência.

A experiência da frente de combate, em que participou entre 1917-18, afecta-o profundamente, permitindo-lhe tomar consciência do sentido da finitude como ser-para-a-morte. Acresce a isso que a derrota alemã difunde entre a população educada um sentimento generalizado de descrença na ciência e filosofia académicas da época bem como na ideologia liberal que as sustenta: a fé cega na evolução pretendida da sociedade para o progresso e a liberdade através do cultivo da racionalidade. A profunda crise cultural e o sentimento de desorientação geral que então afectaram o espaço cultural europeu encontraram a sua expressão também em filosofia, particularmente na denúncia da vacuidade do idealismo filosófico então dominante, de feição kantiana, arredado dos problemas concretos da vida histórica num jogo puramente conceptual e teorético, e na adesão crescente da nova geração a autores ligados à filosofia da vida - Bergson, Simmel, Dilthey e Nietzsche.

A recente tradução das obras de Kierkegaard dava a conhecer ao público alemão a sua crítica, de inspiração cristã, ao idealismo especulativo de Hegel e à sua tentativa de reduzir a existência e sua liberdade inevitavelmente confrontada com alternativas e escolhas - a uma dialéctica especulativa de teor racional, que tudo mediatiza e reconduz a sínteses. ${ }^{15}$ Começa então a emergir na consciência filosófica da época a vontade de desenvolver formas novas e radicais de pensamento, que tenham em conta, não tanto a reflexão ou a mediação racional, como a situação fundamental do homem condenado a escolher e decidir. Karl Jaspers publica em 1919 a Psicologia da Concepções do Mundo, que pode ser considerada a primeira obra de filosofia existencial e na qual se faz um largo apelo a Kierkegaard. As "concepções do mundo"

\footnotetext{
${ }^{15}$ Veja-se, a este propósito, o artigo de H.-G. Gadamer "Existentialismus und Existenzphilosophie", inicialmente publicado em Neue Deutsche Hefte, 28 (1981), pp.675-688 e retomado nas Gesammelte Werke, t. III, Tübingen, 1987, pp. 175-185 .
} 
(Weltanschauungen) são ali apresentadas como atitudes da vontade, que repousam, em última instância, sobre decisões existenciais, sempre tomadas em situações-limite, em que o indivíduo, descobrindo-se como um existente, uma liberdade chamada a determinar-se, se dá conta dos limites da racionalidade científica e do domínio técnico do mundo no plano do agir. ${ }^{16}$

Ao retomar, após o serviço militar, os seus cursos em Friburgo em estreita colaboração com Husserl, Heidegger rompe com a filosofia dos valores ao mesmo tempo que nutre uma desconfiança crescente em relação à Escolástica medieval e à sua construção onto-teológica. Em contrapartida, entrega-se com entusiasmo ao ideário fenomenológico da adesão, sem preconceitos, à livre manifestação dos fenómenos, depositando na filosofia a missão de criar para um povo histórico o seu mundo espiritual através de uma interrogação apaixonada pelo ente em totalidade. As interpretações da verdade como adequação e do ser como objectividade afiguram-se-lhe derivadas e inautênticas, porquanto não dão conta do peculiar modo de ser do sujeito como vida histórica e espiritual. Eleger esta como região ôntica privilegiada para a edificação da ontologia é, doravante, o seu desiderato, pelo que é imprescindível elaborar uma ideia de ser suficientemente ampla para englobar o ôntico e o histórico, a natureza e a liberdade.

Um profundo interesse pelo mundo histórico, que conhecia por dentro sobretudo nos domínios da Teologia e da Filosofia, aproximava o nosso filósofo de Dilthey, da sua compreensão hermenêutica da vida, ao mesmo tempo que o distanciava da orientação idealizante que Husserl vinha conferindo à Fenomenologia. Recusando o "ego transcendental "das Ideen e a teoria da "époché", interpreta à luz de Dilthey o método fenomenológico, não como uma intuição dos fenómenos e seus actos mas como uma compreensão hermenêutica dos complexos de significação mundana, em que se inscreve a vida na sua facticidade. A Fenomenologia é, assim, entendida pelo nosso autor como uma ciência originária da vida,

${ }^{16}$ Conf. Karl Jaspers, Psychologie der Weltanschauung, Berlim, Heidelberg, N. Yorque, 1971. Em 1919, Heidegger, numa longa recensão crítica, ataca Jaspers, radicalizando as suas posições. Aí distingue, pela primeira vez, o seu "pensamento do ser" da filosofia existencial daquele, porquanto esta jamais se interroga pelo sentido de ser do "eu sou", aceitando de bom grado a sua interpretação consensual como subjectividade, sem relevar suficientemente o papel da temporalidade e da historicidade na configuração do sentido fundamental da existência. Conf. Heidegger, Wegmarken: Anmerkungen zu Karl Jaspers "Psychologie der Weltanschauungen”(1919/21), G.A., t. 9, pp. 1-44 (trad.franc.:'Remarques sur la Psychologie der Weltanschauung de Karl Jaspers", Philosophie, n. 11 (1986), pp. 3-21). 
do eu histórico-mundano em situação, onde se originariamente se constitui o sentido. Ela requer, como abordagem, não a apreensão intuitiva e generalizante de um eidos conceptualizável, mas a explicitação do modo como a vida já de si se compreende enquanto agir estruturado significativamente, que maximamente se ilumina no instante da decisão.

Com tudo isto, a antiga problemática aristotélica do sentido do ser e da analogia recebe uma nova leitura por parte de Heidegger. Na verdade, argúi se a investigação teorética se enraíza no grande facto da vida histórica, inobjectivável como um dado para uma consciência teorética, então há de ser no evento da vivência pessoal, isto é, no próprio tecido da temporalidade existencial, que deve ser procurado o sentido do mundo e do ser e, por conseguinte, o fundamento de uma ontologia universal. $\mathrm{O}$ intento restaurador que animara a tese de Habilitação, transforma-se, assim, num projecto mais vasto e ambicioso de desconstrução e de refundação da Metafísica que, descendo às raízes de qualquer interpretação do ser, possa estabelecer as bases de qualquer filosofia vindoura.

De 1919 a 1923, Heidegger elabora as categorias da vida fáctica, a que corresponderão mais tarde os existenciais. Para tal, foi decisiva a sua descoberta da vida fáctica na antropologia de São Paulo e de Santo Agostinho. ${ }^{17} \mathrm{~A}$ seu ver, a experiência cristã primitiva da vida, ali presente, revela o sentido original da existência - a antecipação do nosso ser-para-a-morte, a liberdade para a escolha na situação, o projecto -, mas a sua interpretação pela filosofia faseou-a, cobrindo-a com uma conceptualização inadequada tirada da interpretação grega do ser como presença constante. Ora, o característico da vida, evidenciado por aqueles autores, não é a assimilação do espírito a valores eternos, mas o seu carácter cinético, a sua constitutiva mobilidade, o seu contínuo ir ao encontro de possibilidades mundanas, que cada um tem de assumir neste ou naquele projecto fundamental. O fenómeno, que assim se manifesta e torna presente à existência, não só comporta um velamento - um encobrir de outras possibilidades -, como a sua apreensão e conceptualização é condicionada por um contexto, uma prévia situação hermenêutica sempre recebida e vivida numa determinada situação afectiva.

Com efeito, para o cristianismo primitivo o tempo é o modo como Deus vem ao encontro e se torna presente na mobilidade da vida fáctica. Mas a relação do crente ao futuro, designadamente à promessa da segunda vinda de Cristo, não consiste na espera expectante de um evento ôntico futuro - pois ninguém sabe o "como" e "quando" da vinda -, mas no modo vigilante como desde já se vive a vida, não perdido em ocupa-

${ }^{17}$ Veja-se o curso de Heidegger, de 1920/21, Phänomenologie des religiösen Lebens, G.A., t. 60 . 
ções mundanas, mas numa constante incerteza diante da vinda possível do Deus invisível. ${ }^{18}$ É desta relação existencial à Transcendência que surge um sentido novo de temporalidade, irredutível à concepção cosmológica de um Platão ou Aristóteles. A essa luz, a vida não consiste numa orientação para conteúdos objectivantes, mas num dinamismo de realização temporal sempre aberto a um futuro imprevisível. A estrutura formal do tempo apresenta, por isso, já aquela configuração tripartida e ekstática que será característica de "Ser e Tempo": o momento presente é aberto e co-determinado pelos dois movimentos de auto-transcendência do eu, em direcção ao passado que já se é necessariamente e em direcção ao futuro que se escolheu ser, e de onde provem a norma e o telos do agir. De modo que a temporalidade primordial perfaz o dinamismo ontológico que permite a cada um tornar-se aquilo que já é, ou seja, realizar a sua essência, trazendo desse modo à presença uma dimensão de si ausente, ou seja, actualizando uma possibilidade em si já operativa.

Ao mesmo tempo que aprofunda a sua compreensão do fenómeno humano na sua originalidade, o filósofo adensa a sua crítica à ontologia grega da substância, medindo as suas repercussões negativas na antropologia filosófica moderna, de Descartes a Husserl e Scheler, passando por Kant. A seu ver, aquela última desenvolveu uma concepção cousista da consciência como sujeito permanente de seus actos e um entendimento do homem como espírito, associado a uma alma e um corpo, sem jamais poder explicar a unidade intrínseca destas várias dimensões do seu viver intencional. O primado grego da vida teorética alheou a filosofia desde cedo do terreno genuíno da temporalidade, condenando-a a preterir a existência como lugar da revelação da verdade em prol do plano abstracto das ideias e a entregar-se à tematização da estrutura permanente da realidade. Mas esta, no modo da presença constante do inteligível, do que subsiste como o mesmo através da mudança, não deixa, contudo, de denunciar na figura da permanência a acção sub-reptícia do tempo, reenviando, portanto, o pensar para a questão magna da articulação entre o ser e o tempo.

Ela constituirá, doravante, para Heidegger o enfoque privilegiado a partir do qual vai procurar responder à questão, que Platão e Aristóteles apesar de tudo ainda colocavam, acerca do sentido do ser. Os prejuízos sobre a indefinibilidade e a pretensa evidência do ser não constituem impedimento de maior para levar por diante a investigação. Decerto que, porque não é um ente mas o horizonte a partir do qual este é entendido, o

18 Conf. São Paulo, 1. ${ }^{a}$ Carta aos Tessalonicenses, cap. 5:"Quanto ao tempo e à ocasião, irmãos, não precisais que vos escrevam, pois vós mesmos sabeis que o dia do Senhor virá como um ladrão, de noite. E quando vos disserem: "Paz e segurança!", então é que cairá subitamente sobre eles a ruína, como as dores sobre a mulher grávida e não poderão escapar.” 
ser requer um modo próprio de abordagem, embora sempre a partir do ente, pois é neste que sempre se dá e manifesta. Ora o homem, porque está dotado de uma pré-compreensão do ser, a partir da qual vive e que pode a todo o momento explicitar, constitui o ente mais apropriado para a análise, distinguindo-se mesmo dos demais por essa sua abertura ontológica. Com efeito, dirá Heidegger, ele é mesmo o ente ontológico, cuja essência consiste na existência, na abertura ekstática ao ser, mediante a qual tem acesso a si mesmo e ao ser de todas as coisas. ${ }^{19}$

\section{A Filosofia como lógica produtiva da verdade}

Para terminar o conspecto geral do posicionamento de Heidegger em relação à Metafísica no período de gestação das ideias conducentes a Ser e Tempo, há que referir a sua importante concepção de filosofia como "lógica produtiva da verdade". ${ }^{20}$ Amadurecida através de uma reflexão aprofundada das gnosiologias de Kant e Husserl, ela prende-se com o papel atribuído ao homem na explicitação e constituição da verdade, em consequência de ele perfazer, como ente ontológico, o lugar, a "clareira" (Lichtung) da manifestação. A "produção" em causa na definição acima não se reporta, é claro, ao plano ôntico da experiência em que se movem as ciências na sua caracterização positiva das coisas; antes se refere àquele outro, ontológico, do sentido, que rege e determina o primeiro, porquanto concerne a constituição essencial dos objectos, isso que Kant denominava a "objectividade dos objectos" e Heidegger "o ser do ente".

Note-se, no entanto, que a lógica filosofante que aqui se procura não intenta reger o ser, determiná-lo e violentá-lo pelo conceito, como se aquele fosse um objecto de intuição determinável por categorias. Com efeito, ao contrário do ponto de vista abstracto e teorético da proposição especulativa, em que o resultado - o pensar que a si mesmo se auto-certifica na absolutidade do saber, entretanto, alcançado - tudo determina à

${ }^{19}$ Conf. Sein und Zeit, G.A., t. 2, §4, p.16:'Die ontische Auszeichnung des Daseins liegt darin, dass es ontologisch ist". [A característica ôntica do ser-aí reside nisto, que ele é ontológico.]

${ }^{20}$ Conf. Ibidem, §3, p. 14:"Sie ist productive Logik in dem Sinne, dass sie in ein bestimmtes Seinsgebiet gleichsam vorspringt, es in seiner Seinsverfassung allererst erschliesst und die gewonnenen Strukturen den positiven Wissenschaften als durchsichtige Anweisungen des Fragens verfügbar macht." [Ela é lógica produtiva, no sentido em que projecta um determinado domínio do ser, explora antes de mais a sua constituição de ser e oferece as estruturas assim obtidas às ciências positivas, enquanto indicações evidentes do questionar.] Veja-se ainda o curso de Marburgo de 1925 Prolegomena zur Geschichte des Zeitbegriffs, G.A.,t. $20, \S 1$, p. 2 . 
partida, visa-se aqui um "logos" que provenha do próprio ser, que seja capaz de de-limitar, sem dominar, o que com ele se dá em presença, de fazer aparecer o que é mais inaparente e a dialéctica tende a encobrir, a saber: a ocorrência do tempo, a vinda à presença do presente. O tempo, que assim se temporaliza, exige, com efeito, como melhor veremos mais adiante, um dizer de teor explicitativo e tautológico, que, em vez de reenviar para uma causa explicativa exterior, antes reitere a anterioridade de sentido e de verdade em que já sempre se está.

A filosofia é, portanto, para o nosso filósofo uma ciência ontológica. Ela tem o ser como seu único tema e como tarefa a explicitação e interpretação teórico-conceptual da estrutura, modos e relações que o constituem. ${ }^{21}$ Compete-lhe, por isso, a projecção antecipativa e compreensiva de modos de ver e perspectivar a verdade dos entes naqueles que são os principais domínios do ser - a natureza e a história, entre si interligados por complexo antagonismo e que constituem os campos temáticos das ciências. Ela pode, por isso contribuir, como ontologia universal, para a clarificação e fundação do saber científico, reconduzindo os seus conceitos primários à experiência original e pré-teorética em que se dá a realidade em questão, antes do seu obscurecimento conceptual. ${ }^{22}$ Abre assim novos campos e perspectivas de investigação, estabelece novas vias e critérios para todo o comportamento e decisão, promovendo ou mesmo determinando o avanço historial do homem.

Não se reportando teticamente ao ente, a filosofia não é, por conseguinte, uma ciência ôntica ao lado das outras ciências, não compete com elas nem acrescenta nada à sua caracterização positiva das coisas. Não se propõe também uma mundividência, uma visão de conjunto do ente em totalidade, construída, por exemplo, a partir de uma generalização das representações científicas da época acerca do mundo e do lugar que nele o homem ocupa. Antes lhe cumpre clarificar o sentido que já sempre permeia, antes de toda a objectivação científica, a relação do homem ao ente circundante e o habilita ao conhecimento, explicitar essa estrutura projectiva da compreensão que guia antecipadamente a sua abertura cognitiva ao que e como da realidade. Pode, no entanto, esclarecer a

${ }^{21}$ Conf. o curso de Heidegger, Die Grundprobleme der Phänomenologie, G.A., t. 24, $\S 3$, p. 15:"Philosophie ist die theoretisch-begriffliche Interpretation des Seins, seiner Struktur und seiner Möglichkeiten. Sie ist ontologisch." [A filosofia é uma interpretação teorético-conceptual do ser, da sua estrutura e das suas possibilidades. Ela é ontológica.]

${ }^{22}$ Conf. o curso de Heidegger, Prolegomena zur Geschichte des Zeitbegriffs, G.A., t. 20, §§1 e 2, pp. 1-9 e, também do período de Marburgo, o curso de 1927/28 Phänomenologische Interpretation von Kants Kritik der reinen Vernunft, G.A., t. $25, \S 2$, pp. 17-39. 
razão por que pertence à essência humana a formação de mundivisões. ${ }^{23}$ Recuperando a concepção diltheyiana da filosofia como teoria das concepções do mundo, Heidegger procura, no entanto, esclarecer o que o seu predecessor deixara subentendido: como é que a vida tem acesso a si e constrói essa auto-interpretação, pela qual o sentido e a verdade se tornam o seu modo de ser fundante; como é que pertence à sua essência a formação do mundo, isto é, a constituição do significar e do interpretar com que ente e de que modo ela se pode relacionar e comportar. ${ }^{24} \mathrm{E}$ é aqui que o influxo de Kant se tornou determinante no impulso que deu para a clarificação do problema da transcendência ou compreensão prévia do ser do ente - ou, na terminologia da Crítica da Razão Pura, do conhecimento transcendental, que, para Kant, equivalia ao juízo sintético $a$ priori - como condição de possibilidade da Metafísica.

Com efeito, para Heidegger, Kant viu, pela primeira vez, todas as implicações do problema da finitude para a questão do conhecimento. ${ }^{25} \mathrm{~A}$ tradição entendia a finitude como essa condição do ens creatum que, não sendo causa de si, está dependente de um ente, de um mundo que o precede e com o qual se tem de compaginar. Por conseguinte, a intuição, por onde o conhecimento se efectiva, só pode ser receptiva, ordenada à pré-existência das coisas, ofertando-lhes pela sensibilidade a possibilidade de se manifestarem. Ora Kant, considerando que o sujeito não pode enfrentar sem mais o que já aí está constituído diante dele, desenvolve uma concepção não sensualista, de uma sensibilidade pura, ontológica, em que o tempo e o espaço perfazem as condições gerais da receptividade das impressões produzidas pelos objectos. Mas como o nível fenoménico não chega para que haja conhecimento, Kant vê-se obrigado a estender às

${ }^{23}$ Veja-se Heidegger, Die Grundprobleme der Phänomenologie, § 2, pp. 5-14 e o curso do segundo período de Friburgo, de 1929/30, Die Grundbegriffe der Metaphysik, G.A., t.29/30, especialmente o cap.VI, onde discute a tese do homem como "configurador de mundo".

${ }^{24}$ Sobre a importância e os limites do pensamento de Dilthey, veja-se $S Z, \S 77$, pp. 525-533 e, também de Heidegger, Les Conférences de Cassel (1925), ed. bilingue trad. e anotada por J.-C. Gens, Paris: Vrin, 2003, pp. 170-171, onde, a esse propósito, se pode ler:’Dilthey gelangt dazu, diese Realität (des Geschichtlichseins) zur Gegebenheit zu bringen. Er bestimmt sie als lebendig, frei und geschichtlich. Er stellt aber nicht die Frage nach der Geschichtlichkeit selbst, die Frage nach dem Seinssinn, nach dem sein des Seienden.'[Dilthey consegue isso, transformar a realidade (do ser historial) num dado. Ele determina-a como viva, livre e historial. Mas ele já não coloca a pergunta pela própria historialidade, a pergunta pelo sentido do ser, pelo ser do ente.]

${ }^{25}$ Doravante remetemos para a obra de Heidegger, Kant und das Problem der Metaphysik, 4. ${ }^{\text {a }}$ ed., Frankfurt am Main: V. Klostermann, 1973, de que apresentamos uma sinopse. 
restantes faculdades a estrutura transcendental exigida da sensibilidade. Assim, se o entendimento fornece, com a apodicidade do conceito, o requisito da objectividade, é no entanto à imaginação que fica entregue a sua imprescindível relação à sensibilidade, não sendo sem ela possível o conhecimento. Fornecendo formas ou esquemas sensíveis das categorias, a partir dos quais os objectos da intuição podem ser vistos e pensados, a imaginação é verdadeiramente uma exhibitio originária, formadora, não do objecto ele mesmo, mas do horizonte a partir do qual ele se poderá apresentar na sua objectividade. Heidegger saúda na imaginação a solução do problema da transcendência, isto é, da passagem do sujeito finito, que não é criador do ente que ele conhece, para este mesmo ente distinto através do conhecimento, a qual não é imediata, mas requer uma prévia doação de horizonte ontológico para a recepção ôntica do que se apresenta.

Além da convergência na problemática e da semelhança no modo de conceber a transcendência metafísica, Heidegger valoriza sobretudo em Kant um ponto, para ele de suma importância, a saber, o ter reconhecido no tempo a raiz da compreensão do ser constitutiva da essência humana. Com efeito, no capítulo "Sobre o esquematismo dos conceitos puros do entendimento", em que procura descrever a acção da imaginação na formação de uma imagem pura universal ou "esquema" para o conceito, Kant refere-se, a esse propósito, à projecção do tempo original. Plasmado pela imaginação transcendental no sentido da produção de um horizonte unitário, a partir do qual o objecto possa ser apreendido como algo de permanente e idêntico no processo da sua alteração, esse tempo não é intra-temporal, situa-se no cerne mesmo do sujeito, é a raiz das duas faculdades, o segredo da sua articulação. Isto significa que o sujeito, no mais íntimo da sua subjectividade, é temporalidade, livre doação de um puro horizonte de presença e que esse constitui o fundamento impensado da sua orientação metafísica para o supra-sensível. É claro que Heidegger, na sua interpretação de Kant, vai mais longe do que este, diz o que ele não disse, o que talvez não se atreveu a tematizar, condicionado que estava pela hegemonia da lógica na tradição, o primado do juízo no conhecimento e a compreensão do modo de ser do homem como racionalidade. Mas isso pouco importa para o nosso filósofo: aí está Ser e Tempo para colmatar as lacunas, explicitar o tempo existencial como essência da finitude humana e horizonte da compreensão do ser.

\section{RESUMO}

O presente artigo traça a génese da questão do ser em Heidegger procurando evidenciar a sua íntima articulação com o problema da possibilidade da Metafísica como ciência. Mostra como foi através da leitura de Aristóteles, que o filósofo se 
deu conta da ausência, em Metafísica, de um sentido unitário e abrangente para o conceito de ser e da necessidade de suprir esta lacuna a fim de viabilizar qualquer intento consistente de nova sistemática. A seu ver, os grandes problemas da Ontologia prendem-se com a insuficiente clarificação daquele conceito, designadamente no que concerne a sua relação com o tempo.

Os principais influxos do seu percurso filosófico até ao amadurecimento da problemática da obra-magna Ser e Tempo - o sistema de Metafísica escolástica, o neokantismo e a fenomenologia - são sempre acolhidos do ponto de vista da sua pertinência para a consecução do projecto, que anima o jovem filósofo, de reforma da Metafísica.

No entanto, a experiência da primeira grande Guerra mundial e da crise de sentido dela decorrente fê-lo romper com a dogmática católica e o racionalismo académico da época e procurar junto do protestantismo e da filosofia existencial, então emergente, inspiração para um novo ponto de partida filosófico. $\mathrm{O}$ antigo projecto filosófico radicaliza-se neste outro de teor refundacional: trata-se não apenas de reformar, mas de inovar, lançando as bases de uma nova interpretação do ser a partir do tempo.

Palavras-Chave: ser, metafísica, tempo, Aristóteles, Escolástica, Neokantismo, Fenomenologia.

\section{RÉSUMÉ}

Le présent article décrit la genèse de la question de l'être chez Heidegger, cherchant à mettre en relief son intime relation avec le problème de la Métaphysique comme science. Il montre comment ce fut à travers la lecture d'Aristote que le philosophe s'est rendu compte de l'absence, en Métaphysique, d'un sens unitaire et compréhensif pour le concept d'être et du besoin de suppléer à ce manque a fin de rendre possible quelque propos cohérent d'une nouvelle systématique. Il considère que les grands problèmes de la Métaphysique relèvent d'une insuffisante clarification de ce concept, notamment en ce qui concerne sa relation au temps.

Les principales influences de son parcours philosophique jusqu'au mûrissement de l'œuvre majeure Être et Temps - le système de Métaphysique scolastique, le néo-kantisme, la phénoménologie - sont toujours reçues du point de vue de son possible intérêt pour la réalisation du projet, qui anime alors le jeune philosophe, de réforme de la Métaphysique.

Pourtant, l'expérience de la première grande Guerre Mondiale et de la crise du sens qui partout l'a succédée l'a fait rompre avec la dogmatique catholique et la culture académique du rationalisme régnant et chercher près du protestantisme et de la philosophie existentielle, alors emergente en Allemagne, le souffle pour un nouveau point de départ philosophique. L'ancient projet philosophique se radicalise en cet autre d'accent refondationel: il s'agit non seulement de réformer, mais d'innover lançant les bases pour une nouvelle interprétation de l'être à partir du temps.

Paroles-clés: être, métaphysique, temps, Aristote, Scolastique, Néo-kantisme, Phénoménologie. 